\title{
Evaluasi Usability Aplikasi EDMODO dengan SUS dan Thematic Analysis
}

\author{
Mochammad Arief Hermawan Sutoyo ${ }^{a}$, Puji Rahayu ${ }^{\text {b* }}$ \\ a, Fakultas Ilmu Komputer, Universitas Dinamika Bangsa \\ ${ }^{\mathrm{b}}$ Fakultas Ilmu Komputer, Universitas Mercu Buana
}

Naskah Diterima : 2 Agustus 2021; Diterima Publikasi : 24 Januari 2022

DOI: 10.21456/vol11iss2pp146-151

\begin{abstract}
The Covid pandemic that occurred in 2020 prompted the Indonesian government to issue policies related to distance education (PJJ), to avoid the spread of disease. This sudden appeal caused tertiary institutions and students who were not ready to be ready and accustomed to the situation. To do PJJ at X University, which is located in Jambi province, use EDMODO as an application to do PJJ. The use of EDMODO as a PJJ media has been going on for almost 2 semesters, but the effectiveness of teaching via EDMODO has not been studied for its success, so an analysis is needed related to the application of EDMODO as a PJJ application. The author uses a system usability scale to analyze the educational usability level of this application. From the calculation results, the average value of SUS is 71,2 . However, there is a possibility of decreasing educational usability in this application. So, it is recommended that this application be developed again.
\end{abstract}

Keywords: Distance learning; EDMODO; System Usability

\begin{abstract}
Abstrak
Pandemi covid yang terjadi pada tahun 2020 membuat pemerintah Indonesia mengeluarkan kebijakan terkait pendidikan jarak jauh (PJJ) untuk menghindari penyebaran penyakit. Himbauan yang mendadak ini menyebabkan institusi perguruan tinggi dan mahasiswa yang belum siap harus siap dan membiasakan diri dengan keadaan. Untuk melakukan PJJ pada Universitas X yang terletak di Provinsi Jambi, menggunakan EDMODO sebagai aplikasi guna melakukan PJJ. Penggunaan EDMODO sebagai media PJJ telah berlangsung hampir 2 semester, namun efektifitas pengajaran via EDMODO ini belumlah diteliti keberhasilannya, sehingga diperlukan analisa terkait penerapan EDMODO sebagai aplikasi PJJ. Penelitian ini bertujuan menerapkan system usabillity scale untuk menganalisa tingkat educational usability dari aplikasi tersebut. Dihasilkan bahwa nilai rata-rata SUS menunjukan sebesar 71,2. Hasil tersebut menandakan bahwa aplikasi EDMODO ini masih cukup baik untuk digunakan.
\end{abstract}

Kata Kunci: Pendidikan Jarak Jauh; EDMODO; System Usability

\section{Pendahuluan}

Penggunaan Pandemi COVID-19 yang dirasakan di seluruh dunia sejak akhir 2019 hingga saat ini telah berdampak pada lebih dari 463 juta peserta didik mengalami kesulitan mengakses pembelajaran jarak jauh setelah kegiatan di sekolah dihentikan akibat COVID-19 (UNICEF, 2020). Dampaknya tingkat pemanfaatan platform pendidikan online meningkat secara signifikan (MOAWAD, 2020).

Namun, peralihan pola pembelajaran ke arah pembelajaran jarak jauh memunculkan kekhawatiran terkait kualitas Pendidikan (Sahu, 2020). Maka perlu mengukur tingkat adopsi platform pembelajaran jarak dari aspek proses pembelajaran. Beberapa penelitian juga menyatakan bahwa adopsi dan penerapan platform pendidikan dapat berhasil, jika platform tersebut sebaiknya memiliki tingkat kegunaan yang tinggi.
Di Indonesia Pada tanggal 9 Maret 2020, Kementerian Pendidikan Republik Indonesia mengeluarkan Surat Edaran Nomor 3 Tahun 2020 tentang Pencegahan Covid-19 di unit Pendidikan (Kementerian Pendidikan dan Kebudayaan Republik Indonesia, 2020). Berdasarkan surat edaran tersebut, maka pada tanggal 16 Maret 2020, pemerintah melalui Kementerian Pendidikan mengimplementasikan pembelajaran online sistem dan belajar dari rumah untuk mencegah penyebaran Covid-19 (Kementerian Pendidikan dan Kebudayaan Republik Indonesia, 2020). Hal ini memaksa sebagian besar perguruan tinggi di Indonesia melaksanakan proses belajar mengajar melalui daring dengan dukungan platform pendidikan (Google Classroom, Moodle, EDMODO) ataupun media sosial (Facebook, Instagram, Youtube, Telegram, WhatsApp, LINE). Akan tetapi penggunaan media sosial tetap menjadi dominan meskipun memiliki keterbatasan dalam

\footnotetext{
*) Penulis korespondensi: puji.rahayu@ mercubuana.id, puji.rahayu41@ui.ac.id
} 
proses monitoring dan evaluasi pembelajaran. Berdasarkan hal tersebut, maka penelitian ini akan mengukur tingkat adopsi EDMODO sebagai platform pembelajaran jarak jauh yang memiliki kemiripan bentuk dengan sosial media.

Dalam penelitian terdahulu ada beberapa kajian terhadap pengukuran kegunaan EDMODO di perguruan tinggi yang melibatkan 34 mahasiswa Federal University of Amazonas (UFAM), Brasil (Nakamura et al., 2019). Hasilnya menunjukkan bahwa mahasiswa menganggap aspek kegunaannya positif. Namun, sekitar $41 \%$ responden di kedua kelompok menemui kesulitan teknis dalam melakukan evaluasi, hal ini menjadi pertimbangan untuk memperbaiki atau mengembangan teknik evaluasi. Penelitian lain yang dilakukan di Departemen IT, Fakultas Sains Tishk International University, Iraq yang bertujuan untuk mengetahui faktor usability yang mempengaruhi pembelajaran dengan pendekatan Technology Acceptance Model (TAM (Sultan et al., 2020)). Hasil penelitian tersebut menunjukkan bahwa EDMODO sangat bagus dan mampu untuk memperkirakan kegunaan dan tidak sulit digunakan. Kajian lain terkait uji usability penggunaan EDMODO di Amasya University, Turki dengan menerapkan mixed method, penelitian kuantitatif mengukur aspek kegunaan dengan Skala Kegunaan Sistem (SUS) oleh 12 fakultas (Emiroğlu, 2019). Didapati bahwa aplikasi EDMODO memperoleh skor aspek kegunaan diatas skor ratarata.

Merujuk pada penelitian tersebut, diketahui bahwa minimnya kajian usability terhadap platform EDMODO di tingkat perguruan tinggi dibandingkan kajian yang dilakukan di Sekolah. Kesenjangan penelitian ini coba diatasi dengan melakukan studi tentang pengukuran aspek kegunaan EDMODO dengan studi kasus di fakultas ilmu komputer, Universitas X. Metode yang digunakan dalam penelitian ini adalah metode SUS yang diperkenalkan oleh Sauro et al (2021). Hasil analisis SUS akan divalidasi dengan pendekatan kualitatif menggunakan Tematik Analisis.

\section{Landasan Teori}

Dalam kajian evaluasi usability aplikasi Edmodo, ada tiga topik penting yang menjadi dasar yaitu konteks e-learning dan asepek kegunaan, serta Edmodo. Berikut penjelasannya

\section{1. e-Learning dan, Aspek Kegunaan}

Aspek Kegunaan mengacu pada kemampuan menggunakan sistem dengan cara yang mudah . Usability juga dapat diartikan, sebagai seberapa banyak pengguna menikmati menggunakan sistem menurut (Dictionary, 2022). Strohmann dkk. memberikan pedoman untuk faktor kegunaan di HCI agar dapat mudah dipahami, dioperasikan, dapat dimengerti dan menjadi elemen kunci dalam usability (Strohmann et al., 2019). Kegunaan yang dirasakan adalah aspek penting dari kerangka kegunaan yang diinisiasi oleh Gunesekera (Gunesekera, 2019).

System Usability Scale (SUS) menurut Brooke muncul dari periode tersebut dan menjadi instrument dalam mengukur standar kegunaan yang paling banyak diterapkan dibandingkan alat ukur lain seperti CSUQ, PSSUQ dan UMUX memperoleh 15\% (Díazoreiro et al., 2019; Lewis, 2018). Beberapa penelitian menunjukkan bahwa SUS memiliki tingkat reliabilitas yang tinggi, dengan koefisien alpha yang normal diatas 0,90 , dan validitas yang sangat baik serta peka terhadap berbagai variabel independen baik di laboratorium maupun survei (Garcia et al., 2018).

Dalam penelitian ini, kami merujuk pada Sharfina dan Santoso (Sharfina dan Santoso, 2017) sebagai instrument pengumpulan data. Bentuk pertanyaan dalam Bahasa Indonesia dapat dilihat pada tabel 1 .

Tabel 1. Pertanyaan SUS berbahasa Indonesia

\begin{tabular}{cl}
\hline No & \multicolumn{1}{c}{ Item in Indonesia } \\
\hline 1 & Saya berpikir akan menggunakan sistem ini lagi \\
2 & Saya merasa sistem ini rumit untuk digunakan \\
3 & Saya merasa sistem ini mudah untuk digunakan \\
4 & $\begin{array}{l}\text { Saya membutuhkan bantuan dari orang lain atau } \\
\text { teknisi untuk menggunakan sistem ini }\end{array}$ \\
5 & $\begin{array}{l}\text { Saya merasa fitur-fitur sistem ini berjalan dengan } \\
\text { semestinya }\end{array}$ \\
6 & $\begin{array}{l}\text { Saya merasa ada banyak hal yang tidak konsisten/tidak } \\
\text { serasi pada sistem ini }\end{array}$ \\
7 & $\begin{array}{l}\text { Saya merasa orang lain akan memahami cara } \\
\text { menggunakan sistem ini dengan cepat }\end{array}$ \\
8 & $\begin{array}{l}\text { Saya merasa sistem ini membingungkan } \\
\text { Saya merasa tidak ada hambatan dalam menggunakan } \\
\text { sistem ini }\end{array}$ \\
10 & $\begin{array}{l}\text { Saya perlu membiasakan diri terlebih dahulu sebelum } \\
\text { menggunakan sistem ini }\end{array}$ \\
\hline
\end{tabular}

\section{3. $E D M O D O$}

Saat ini bentuk konten e-learning interaktif yang banyak diadopsi dalam pendidikan tinggi adalah Sistem Manajemen Pembelajaran (LMS) dan Pembelajaran Sosial Jaringan (SLN). Sejumlah platform LMS dan SLN terkini banyak muncul, masing-masing menawarkan aspek kegunaan yang berbeda kepada penggunanya. Contohnya antara lain adalah Blackboard (BB), Desire2Learn (D2L), dan Moodle. EDMODO SLN adalah platform pembelajaran yang digunakan di sekolah dan universitas yang digunakan untuk memfasilitasi kerjasama antar siswa, rekan kerja, dan instruktur. (Kongchan, 2008).

EDMODO Juga disebut sebagai layanan mikroblogging, situs web atau forum jejaring sosial (Alnaibin et al., 2018), sistem manajemen pembelajaran berbasis internet, media sosial asinkron berbasis text (Lam et al., 2017), dan platform pembelajaran interaktif berbasis cloud atau Facebook for pendidikan tinggi.

Berbeda dengan situs jejaring sosial umum (SNS) seperti Facebook, EDMODO berorientasi pada 
Pendidikan. EDMODO bahkan diakui sebagai LMS (Al-naibi et al., 2018). Platform ini tidak hanya memfasilitasi pertukaran konten pembelajaran dalam kelas yang dapat merangsang kolaborasi komunikasi dan minat pembelajaran (Kerpen et al., 2020).

\section{Metode}

Penelitian dilakukan secara kuantitatif dan kualitatif penelitian ini terbagi menjadi 4 tahapan, detail tahapan dapat dilihat pada gambar 1 .

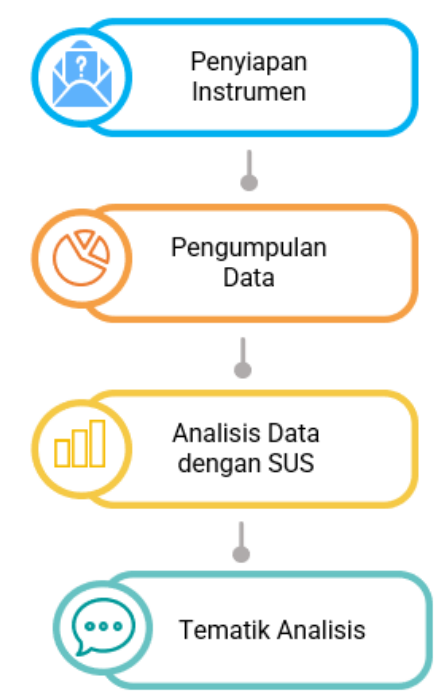

Gambar 1. Metodologi Penelitian

\subsection{Persiapan instrument penelitian}

Penelitian ini menggunakan kuesioner sebagai intrumen pengumpulan data.

Kuesioner diidentifikasi sebagai instrument yang paling sesuai untuk penelitian ini karena sejumlah besar data dapat dikumpulkan secara real time, dan mudah dipahami bagi sebagian besar responden. Kuesioner dibuat berdasarkan konsep SUS mengacu pada tabel 1, dengan penambahan pertanyaan terkait demografi, waktu penggunaan internet dan konsep/saran terkait kemudahan penggunaan EDMODO. Pertanyaan kemudian disebarkan secara daring melalui Google Formulir. Keterlibatan mahasiswa sebagai responden dalam studi ini bersifat sukarela dan tidak mengikat.

Kuesioner terdiri dari 3 bagian. Bagian Pertama berfokus pada demografi civitas akademik dan penggunaan EDMODO, termasuk jenis kelamin, usia, dan latar belakang pendidikan. Bagian Dua pengukuran SUS. Bagian Tiga berisi pertanyaan terbuka yang diperuntukkan bagi dosen agar dapat memberikan perhatian atau saran tambahan terkait dengan kegunaan EDMODO. Untuk membatasi pengaruh urutan penyajian SUS diacak. Kuesioner juga diujicobakan dengan tiga anggota fakultas sebelum distribusi, untuk memastikan kejelasan instrumen penelitian.

\subsection{Pengambilan data}

Penelitian ini dilakukan dan kuesioner disebar dari rentang waktu desember 2020 sampai dengan januari 2021. Dari pembagian kuesioner, didapatkan 112 responden, semua responden adalah mahasiswa semester 5 di Universitas X. 112 responden lebih dari cukup untuk akurasi prediksi dari SUS, sebab dengan 15 responden rata-rata nilai SUS dari yang diuji dapat diketahui secara pasti (walau ditambah, tidak banyak berpengaruh).

Hasil dari kuesioner yang disebar pada 112 responden memberikan respon yang cukup beragam mengenai penggunaan aplikasi EDMODO.

\subsection{Analisis Usability dengan SUS}

Metode analisis Usability adalah dengan pendekatan SUS yang diperkenalkan oleh Sauro dkk (Sauro \& Lewis, 2012). Penyelidikan dilakukan berdasarkan bedasarkan konsep skor analisis penerimaan SUS. Modifikasi instrumen SUS dimungkinkan menurut Bangor dan Lewis. SUS terdiri dari 10 instrumen. Instrumen kuesioner SUS tersebut memiliki pernyataan positif dan negatif Skala respons dalam semua kasus berkisar dari 1 (sangat tidak setuju) hingga 5 (sangat setuju). Standar perhitungan dalam skala penilaian SUS menggunakan skala penilaian absolut dengan A:> 89; B: 80-89; C: 70- 79; D:60- 69; dan F: <60.

Adapun daftar pertanyaan SUS yang kami susun ada pada lampiran 1 .

\subsection{Tematik Analisis}

Dalam penelitian ini, pengolahan data kualitatif yang terdiri dari data wawancara dengan mahasiswa dan dosen dan data kuesioner (pertanyaan terbuka) dianalisa menggunakan Perangkat lunak Maxqda 18, yaitu alat perangkat lunak analisis data, digunakan dalam analisis tematik (Braun et al., 2021). Adapun tahapan dalam tematik analisis adalah sebagai berikut:

1. Peneliti melakukan dua kali penyimpanan data.

2. Kata kunci dikodekan secara sistematis, dan data yang relevan dan terkait dengan kata kunci untuk setiap kode disusun.

3. Kode disusun menjadi tema penting. Para peneliti pertama-tama harus melakukan proses koding dengan mengkodekan 10-50\% data, dan kemudian melakukan pemeriksaan uji keandalan pengkodean oleh pembuat kode lain (Roberts et al., 2019)

4. Penulis dan pembuat kode independen meninjau tema untuk memastikan tema tersebut relevan dengan pertanyaan penelitian dan data yang dimiliki. Modifikasi skema pengkodean terus diulang untuk mendapatkan hasil tema yang terbaik.

5. Tema diberi nama dan deskripsi. Pada langkah terakhir, laporan analisis ilmiah dibuat. Setelah selesai, pembuat kode independen memeriksa 
silang semua klasifikasi kata dan pengkodean agar Reliabilitas inter-coder hasilnya $>0,7$.

\section{Hasil dan Pembahasan}

\subsection{Demografi data responden}

Berdasarkan hasil pengumpulan data diketahui $70 \%$ responden berjenis kelamin perempuan, dan responden laki-laki berjumlah $30 \%$ dari total responden. Berdasarkan kategori pekerjaan didapati sejumlah mahasiswa memiliki pekerjaan ganda, ada yang bekerja sebagai karyawan, berjumlah 13 orang, mahasiswa yang berprofesi sebagai PNS sebanyak 1 orang, yang berprofesi sebagai Polri/TNI sebanyak 2 orang, dan yang berprofesi sebagai honorer sebanyak 1 orang.

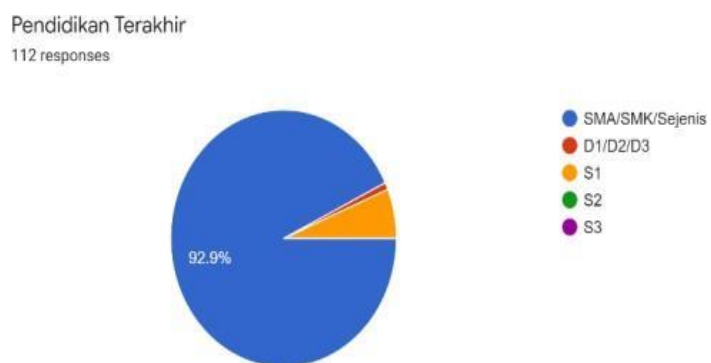

Gambar 2. Pendidikan Terakhir Responden

Sebagian besar usia responden berkisar 18-22 tahun. Gambar 2, menjelaskan latar belakang responden didominasi oleh lulusan SMA/sejenisnya, sedangkan data yang paling minim ada pada responden yang berpendidikan S1 dan D1 dengan jumlah sebesar $8 \%$ /8 orang dari total responden

\subsection{Hasil Pengukuran SUS}

Menurut hasil pengumpulan data menggunakan instrumen SUS, didapati beragam respon terkait penggunaan EDMODO dalam proses belajar gambar 3.

Pada gambar 4, hasil kajian SUS memperlihatkan bahwa lebih dari $60 \%$ responden menyatakan akan kembali menggunakan EDMODO sebagai media pembelajaran jarak jauhnya. Dapat diketahui juga bahwa dalam penggunaan EDMODO, lebih dari $70 \%$ responden dapat langsung menggunakan aplikasi ini tanpa bantuan orang lain. Responden merasa bahwa aplikasi EDMODO tidaklah membingungkan untuk digunakan, karena $75 \%$ pengguna menyatakan bahwa aplikasi ini tidak membingungkan. Responden menyatakan bahwa mereka memerlukan waktu untuk membiasakan diri dalam menggunakan aplikasi ini.

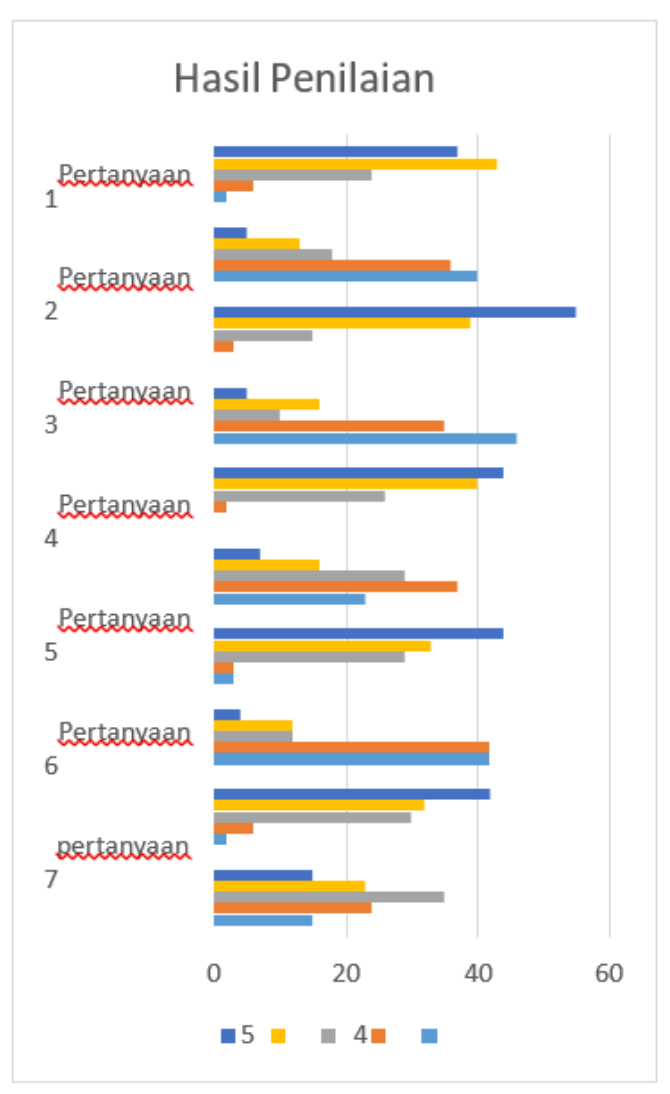

Gambar 3. Skor SUS

\subsection{Hasil Analisa Tematik}

Setelah proses penyelidikan dengan SUS dilakukan, didapati beragam respon terkait penggunaan EDMODO dalam proses belajar mengajar. Beberapa hasil tersebut ditampilkan dalam gambar 4.

Dari gambar 4 diperoleh skor SUS sebesar 71,2, hasil tersebut menunjukkan bahwa EDMODO masih dapat diterima (acceptable) untuk digunakan sebagai media pembelajaran jarak jauh. Untuk uji usability berdasarkan dari pertanyaan sus ke 8 di gambar 2, menandakan bahwa usability dari aplikasi ini baik sebab $75 \%$ pengguna tidak kesulitan menggunakannya. Sedangkan untuk learnability nya dalam pertanyaan 4 dan 10 dinyatakan bahwa walau banyak pengguna tidak kesulitan menggunakannya namun pengguna masih perlu untuk membiasakan diri untuk menggunakan EDMODO.

Jika mengacu pada paper (Sobodić et al 2018), maka user experience dan educational usability nya tidak akan jauh beda dari usability ini yang bermakna bahwa aplikasi ini cukup baik untuk dilanjutkan penggunaannya.

Namun karena aplikasi ini sudah lama digunakan maka bisa saja ada peningkatan $11 \%$ dari nilai, karena user terbiasa dengan aplikasi ini (Díaz-oreiro et al., 2019; Kerpen et al., 2020). Hal ini mengakibatkan nilai yang didapatkan menurun dan acceptability aplikasi EDMODO ini bisa berada di daerah tepi/marjinal. 


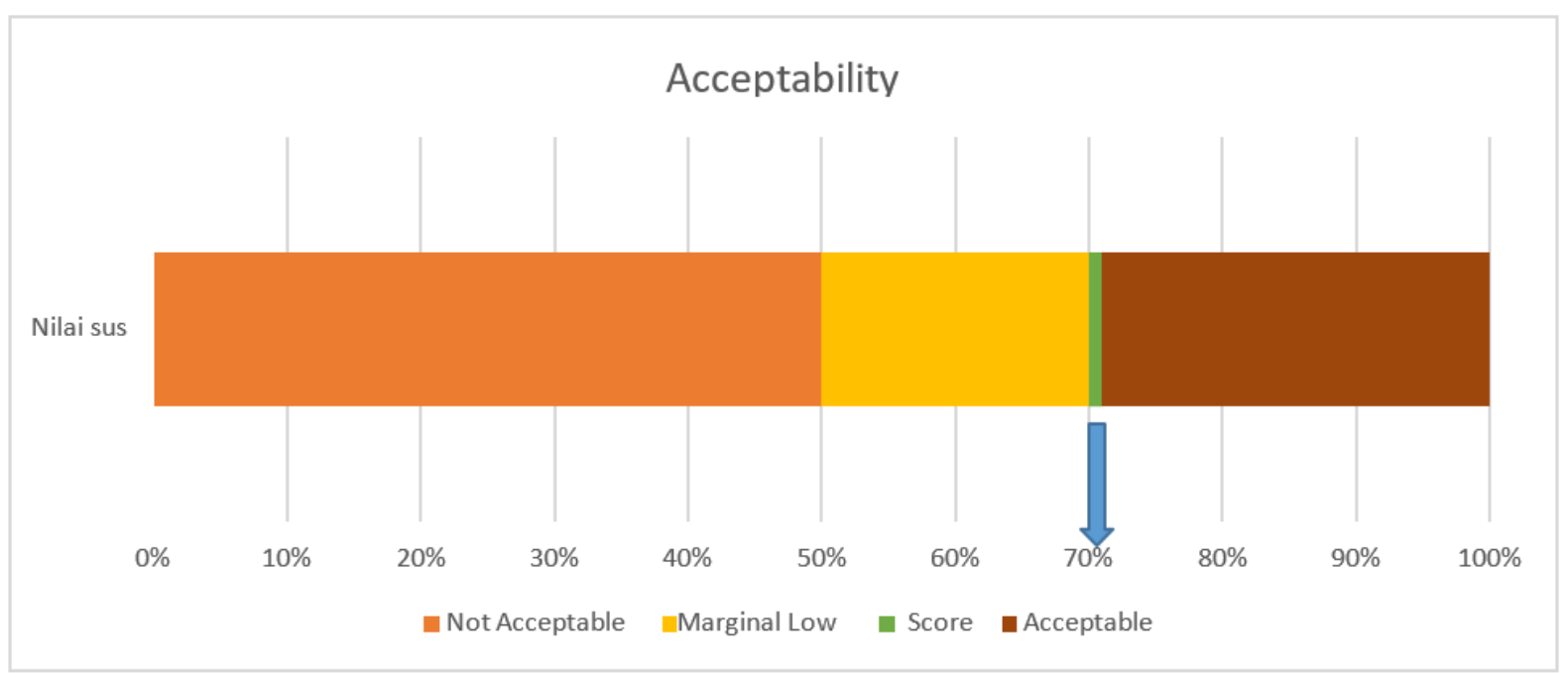

Gambar 4. Nilai SUS

Hal ini diperkuat kajian tematik dari hasil dari open question, didapatkan bahwa hanya 52 responden yang menggunakan aplikasi lain sebagai media pembelajaran jarak jauhnya. Dibandingkan dengan aplikasi pembelajaran jarak jauh lainnya, aplikasi EDMODO memiliki beberapa kelebihan dan kekurangan. Kelebihan yang dikatakan user adalah kemudahan penggunaannya, namun memiliki beberapa kekurangan seperti seringnya postingan user menghilang, notifikasi lambat dan sering tidak muncul, error aplikasi sering terjadi dan jika dibandingkan dengan aplikasi pembelajaran jarak jauh lainnya, UI di aplikasi lain lebih baik dari EDMODO. Hasil ini sejalan dengan penelitian dari Lam et al. (2017), bahwa aplikasi EDMODO membutuhkan User Interface yang lebih terkini dengan performa yang lebih cepat.

Jumlah kata postif dan negatif yang dominan dapat dilihat pada gambar 5, yang menampilkan wordcloud berdasarkan analisa tematik yang didapatkan penulis.

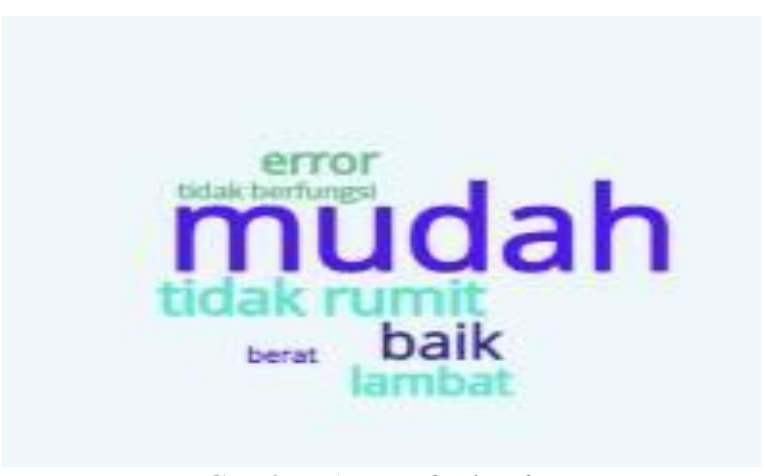

Gambar 5. Word Cloud

\section{Kesimpulan}

Kesimpulan dari penelitian ini menunjukkan bahwa aplikasi EDMODO masih cukup baik untuk digunakan untuk proses PJJ pada Universitas X. Namun, penelitian mendalam diperlukan untuk menemukan efektivitas dan kendala yang dihadapi oleh Mahasiswa dalam kegiatan PJJ ini dan diperlukannya penggunaan aplikasi lain atau pengembangan dari aplikasi ini agar proses belajar dan mengajar dapat menjadi lebih baik. Penggunaan SUS sebagai alat untuk meneliti hanya menjadi titik acuan untuk melakukan penelitian selanjutnya, dari penelitian ini didapatkan gambaran penelitian selanjutnya yang akan dilakukan terkait aplikasi pembelajaran jarak jauh yang nantinya akan dikembangkan di Universitas X.

\section{Daftar Pustaka}

Al-naibi, I., Al-Jabri, M., Al-Kabani, I., 2018. Promoting students paragraph writing using EDMODO. An Action Research. TOJET: The Turkish Online Journal of Educational Technology, 17(1): 130-143.

Braun, V., Clarke, V., Braun, V., Clarke, V., 2021. Qualitative research in psychology one size fits all ?. Qualitative Research in Psychology, 18(3): 328-352.

Díaz-oreiro, I., López, G., Quesada, L., Guerrero, L. A., 2019. Standardized questionnaires for user experience evaluation. A Systematic Literature Review. In MDPI Proceedings (pp. 1-12).

Dictionary, C., 2022. Usability Definition. In Cambridge Dictionary. Retrieved from https://dictionary.cambridge.org/dictionary/engli sh/usability

Emiroğlu, B.G., 2019. Investigating faculty members' perceived usability of edmodo learning management system. Adlyaman Üniversitesi Eğitim Bilimleri Dergisi, 9(1): 159-176.

Garcia, R., Falkner, K., Vivian, R., 2018. Systematic literature review: Self-Regulated Learning 
strategies using e-learning tools for Computer Science. Computers \& Education, 123 :150-163.

Gunesekera, A.I., 2019. The role of usability on elearning user interactions and satisfaction: a literature review. Journal of Systems and Information Technology, 21(3): 368-394.

Kementerian Pendidikan dan Kebudayaan Republik Indonesia, 2020. Surat Edaran Tentang Pencegahan Wabah COVID-19 di Lingkungan Satuan Pendidikan Seluruh Indonesia, Mendikbud RI.

Kerpen, D., Conrad, J., Wallach, D., 2020. A Formalisation Approach For Collaborative User Experience Design. International Design Conference - Design 2020: 947-956.

Lam, Y.W., Hew, K.F., Chiu, T.K.F., 2017. Gamification Improving argumentative writing: Effects of a blended learning approach and gamification. Language Learning \& Technology, 22(1):97-118.

Lewis, J.R. 2018. Measuring Perceived Usability: The CSUQ, SUS, and UMUX Measuring Perceived Usability: The CSUQ, SUS , and UMUX. International Journal of HumanComputer Interaction ISSN:, 7318 (January). https://doi.org/10.1080/10447318.2017.1418805

Lima, I.B., Jeong, Y., Lee, C., Suh, G and Hwang, W., 2021. Severity Of Usability Problems And System Usability Scale (Sus) Scores On Augmented Reality (Ar) User Interfaces. ICIC International 2021. 12(2):175-183. https://doi.org/10.24507/icicelb.12.02.175

MOAWAD, R.A. 2020. Online learning during the COVID- 19 pandemic and academic stress in university students. Revista Românească Pentru Educaţie Multidimensională, 12(1): 100-107. https://doi.org/10.1145/3406601.3406632.

Nakamura, W.T., Marques, L.C., Rivero, L., De Oliveira, E.H.T and Conte, T., 2019. Are scalebased techniques enough for learners to convey their UX when using a Learning Management System? Revista Brasileira de Informática $\mathrm{Na}$ Educação, 27(01): 104.
Roberts, K., Dowell, A. and Nie, J., 2019. Attempting rigour and replicability in thematic analysis of qualitative research data; a case study of codebook development. BMC Medical Research Methodology. 1-8hlm. https://doi.org/https://doi.org/10.1186/s12874019-0707-y (2019).

Sahu, P., 2020. Closure of universities due to coronavirus disease 2019 (COVID-19): impact on education and mental health of students and academic staff. Cureus, 2019(4): 4-9. https://doi.org/10.7759/cureus.7541.

Sharfina, Z. and Santoso, H.B., 2017. An Indonesian adaptation of the System Usability Scale (SUS). 2016 International Conference on Advanced Computer Science and Information Systems, ICACSIS 2016, 145-148. https://doi.org/10.1109/ICACSIS.2016.7872776

Sobodić, A., Balaban, I. and Kermek, D., 2018. Usability metrics for gamified e-learning course: A multilevel approach. International Journal of Emerging Technologies in Learning, 13(5): 4155.

Strohmann, T., Höper, L and Robra-bissantz, S., 2019. Design guidelines for creating a convincing user experience with virtual in-vehicle assistants. In Proceedings of the 52nd Hawaii International Conference on System Sciences. 6 : 4813-4822.

Sultan, N.A., Al-Othman, M.S. and Warttan, H.A., 2020. Exploring student's acceptance of an edmodo learning management system in advanced mobile applications course. PervasiveHealth: Pervasive Computing Technologies for Healthcare, 2, 974-982. https://doi.org/10.4108/eai.28-6-2020.2298085

UNICEF, 2020. Responding to COVID-19: UNICEF Annual Report 2020. New York: United Nations Children's Fund (UNICEF). 